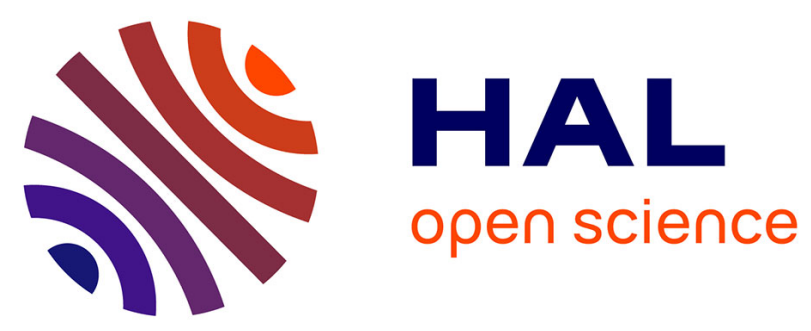

\title{
Towards an Effective Robotic Device for Gait Rehabilitation of Children With Cerebral Palsy
}

Boutheina Maalej, Ahmed Chemori, Nabil Derbel

\section{To cite this version:}

Boutheina Maalej, Ahmed Chemori, Nabil Derbel. Towards an Effective Robotic Device for Gait Rehabilitation of Children With Cerebral Palsy. SCC 2019 - 1st IEEE International Conference on Signal, Control and Communication, Dec 2019, Hammamet, Tunisia. pp.268-273, 10.1109/SCC47175.2019.9116141 . lirmm-02426698

\section{HAL Id: lirmm-02426698 \\ https://hal-lirmm.ccsd.cnrs.fr/lirmm-02426698}

Submitted on 2 Jan 2020

HAL is a multi-disciplinary open access archive for the deposit and dissemination of scientific research documents, whether they are published or not. The documents may come from teaching and research institutions in France or abroad, or from public or private research centers.
L'archive ouverte pluridisciplinaire HAL, est destinée au dépôt et à la diffusion de documents scientifiques de niveau recherche, publiés ou non, émanant des établissements d'enseignement et de recherche français ou étrangers, des laboratoires publics ou privés. 


\title{
Towards an Effective Robotic Device for Gait Rehabilitation of Children With Cerebral Palsy
}

\author{
Boutheina Maalej ${ }^{1}$, Ahmed Chemori ${ }^{2}$ and Nabil Derbel ${ }^{3}$
}

\begin{abstract}
The objective of this study is to focus on the feasibility of a robotic solution for rehabilitation of children with Cerebral Palsy (CP). For this purpose, to restore the walking abilities and in order to stimulate the brain functionality, two rehabilitation techniques have been compared (a conventional rehabilitation and a robotized one). Results indicate that the key of a performant exoskeleton with a good tracking of the gait cycle is to use robust controllers to guarantee the tracking even with kids' parameter variations. A PD controller and a sliding mode controller are implemented and compared in order to prove the difference of their robustness. Through the proposed solution, it has been shown that sliding mode control is more robust than PD controller.
\end{abstract}

Keywords - Rehabilitation, Children, Cerebral palsy, Exoskeletons, PD controller, Sliding mode controller.

\section{INTRODUCTION}

Robotic technologies in rehabilitation are rapidly expanding fields. Since 1980, several appeared ideas combine the technology evolution in robotic domains with the high brain capacity [1]. In fact, studies on animals and humans prove that the reorganization of the brain is highly dependent on the intensity and the magnitude of the sensory motor activities [2]. Physical exercises are important to reduce the spasticity of muscles, especially for early age [3]. The cerebral palsy [4] is the most neurological disease that causes balance and speech impairments, as well as the motor disability. According to the statistics, between 2000 and 2010, in Switzerland, $39 \%$ of 2 -year old children and $58 \%$ in USA have been suffering from cerebral palsy [5]. The cerebral palsy can appear due to several risk factors [6] such as congenital malformations, fetal growth restriction [7], infection during the fetal and neonatal period [8], untreated maternal hypothyroidism, perinatal stroke and premature birth (up to $15 \%$ of more risk for kids who were born between 24 and 27 weeks of gestation) [9]. Therefore, the rehabilitation should focus on improving the locomotor function by training [10]. The training can provide a sufficient and appropriate initialization of the restructuring of neurons within the spinal cord. The lost of the functional mobility may be caused by muscle weaknesses, contracture in joint levels and spasticity (less of foot contact with the floor). Nowadays, many companies

\footnotetext{
${ }^{1}$ Boutheina Maalej is with University of Sfax, ENIS, Laboratory of Control \& Energy Management, Digital Research Center of Sfax, Clinical Investigation Center, Sfax, University of Gabes, Tunisia malej.boutheina@gmail. com

${ }^{2}$ Ahmed Chemori is with LIRMM, University of Montpellier, CNRS, 161 rue Ada, 34392 Montpellier, France ahmed. chemori@lirmm. fr

${ }^{2}$ Nabil Derbel is with University of Sfax, ENIS, Laboratory of Control \& Energy Management, Digital Research Center of Sfax, Tunisia n.derbeldenis.rnu.tn
}

worldwide sell robotic rehabilitation devices (eg. Lokomat, Andago, Armeo, etc) for children in order to restore their walking ability. Mainly two types of applications using these devices exist; namely assistance or rehabilitation. Rehabilitation intends to improve and facilitate the motor function progress by training therapy, while assistance aims to cover the absent motor skills by providing a natural mobility even with paralyzed limbs. Usually, two therapists at least should help a child (in case of an obese child or child who has a severe paresis) to move his legs along a normal gait scheme. Besides, one session can take a long time which may annoy children. Currently, the robotic rehabilitation shows a great importance. In fact, it improves the conventional rehabilitation outcomes and allows kids to exploit their full potential of recovery. Moreover, some devices include biofeedback systems to allow therapists to get more details about the gait phases and applied forces, and allow patients to get direct feedback during sessions. There exist five systems used for lower limbs rehabilitation: (i) treadmill training with a body weight support (Lokomat), (ii) body weight support with programmable foot plate, (iii) over ground training (Andago), (iv) stationary robotic training, and foot orthoses. Besides, other methods of rehabilitation exist such as the use of a humanoid robot to initiate the joint attention of children. Indeed, the robot used to motivate the child to repeat different scenarios of motion training. Approximately, $40 \%$ of children with cerebral palsy who begin the the conventional rehabilitation in an early age, can restore their normal gait. For the rest, the handicap ratio decreases and it depends on the rate of spasticity.

When considering the posture variations and the physical deformities [11] of kids suffering from cerebral palsy, the control of such systems seems to be the most important part of research. In fact, it is necessary to propose advanced controllers which are robust against the parameter variations of children.

This paper is organized as follows. Section II describes the cerebral palsy, its background and its effects on the pediatric population. Section III introduces the rehabilitation methods. Sections IV describes the used simplified model, the proposed control solutions, and simulation results. Finally, Section V presents our conclusion and future works.

\section{Cerebral Palsy Disability}

\section{A. Background on Cerebral Palsy}

Cerebral palsy $(\mathrm{CP})$ is the most common physical handicap of childhood with a rate of 2 to 3 per 1000 births [12]. It has several effects on the children and their families. Indeed, 
it limits the potential development. Besides, the medical treatments are costly and necessary in the same time.

There are three types of cerebral palsy [13]: (i) diplegia, where both arms or both legs are damaged, (ii) hemiplegia, where only one side of the kids' body is diseased and (iii) tetraplegia, when both upper and lower limbs are affected. The principal part responsible of the muscle control is the primary motor cortex. Hence, several neurological diseases in the brain can lead to a muscle disorder as illustrated in Fig. 1.

The common ability of children is that the brain shows a
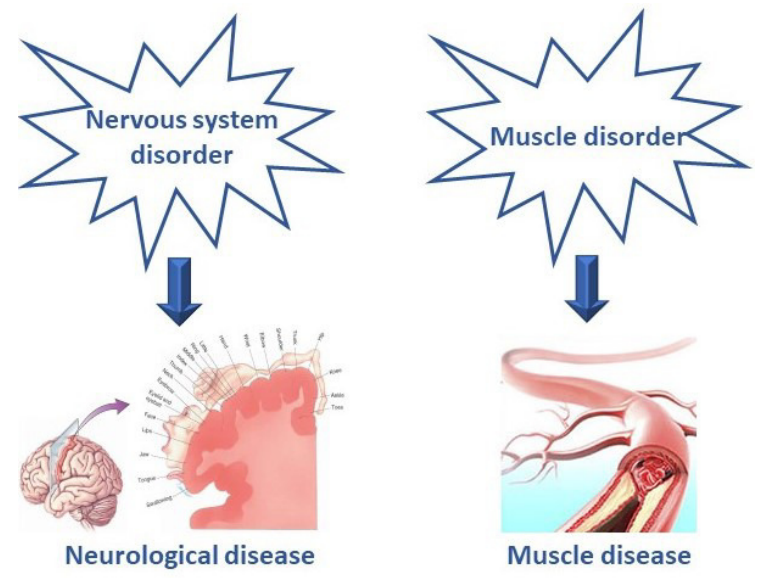

Fig. 1. Neurological and muscle diseases

certain plasticity, which is an intrinsic property of the brain that enable the adaptation to the environment, the psychological transformations and the new experiences. There are different modes of the cerebral plasticity [14] including (i) intensity variation of the cerebral activity, (ii) extension of the active zones near the healthy zone which means the mobilization of the inactive regions in the absence of lesions to active ones, and (iii) development of new regions distant from the functional area. To stimulate the brain plasticity, an effective rehabilitation with a work intensity, an active participation with a regular repetition of gestures and taskoriented exercises are needed. Besides, several influencing factors can be involved such as the age of the child and the type and rapidity development of the lesion. Hence, the walk training may improve motor skills and reorganizes the functional structure of the primary motor cortex, which increases the surface of the cortical maps (remapping: displacement of brain functionalities to a nearby area).

\section{B. Pediatric Population}

Within the first two years, infants can develop $100 \%$ of their body. Hence, they can elaborate their first steps of walking. Some diseases can affect and delay their locomotor ability at birth or even after, such as the cerebral palsy. According to the statistics, 10000 babies are affected by the cerebral palsy each year worldwide [15]. This disease can only be diagnosed once in a lifetime, during pregnancy or from 1 to 2 years old. Indeed, 35\% of infants and newborns may present the risk of muscle weakness with ankle dorsiflexors and plantarflexors, compared to normal children [16]. Hence, it seems necessary to find an efficient solution for this population. Nowadays, it does not exist any cure but several treatments are used, such as tendon lengthening [17], releases, selective dorsal rhizotomy [18], Botulinum toxin injections [19], Baclofen, stretching, orthotics, and robotic rehabilitation [20]. Recently, various studies have proved the efficiency of the robotic systems in walking training. In the sequel, the two rehabilitation techniques are presented.

\section{REHABILITATION TECHNIQUES}

\section{A. Standard Rehabilitation}

Rehabilitation therapy is intended for babies, children or teenagers suffering from different kinds of disorders. In this section, we will focus on delayed motor development. The goal of this therapy is to improve and maintain child's quality of life, promote his/her social reintegration and teaching him the appropriate actions and exercises. The standard therapy is a conventional technique of rehabilitation where physiotherapists focus on the rehabilitation of the functional capacities of children. Since the child capacities are relatively low, therapists try to correct all deformities and improve the patient's activity based on their own estimation. In fact, young children have greater brain plasticity than adults. For this reason, an intervention at an early age is recommended to change the motor patterns.

Several are the therapeutic exercises used for children rehabilitation (cf. illustration of Fig. 2).
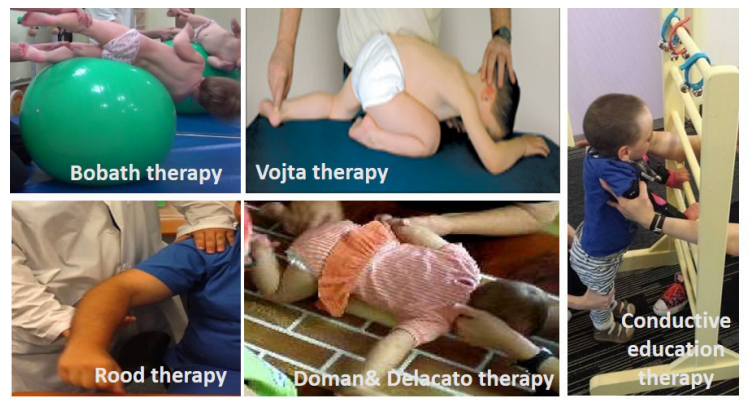

Fig. 2. Different therapy methods for kids rehabilitation

Among these exercises used for children suffering from cerebral palsy, one can cite [21] :

- Doman and Delcato: a series of repetitive exercises, aiming to achieve brain dominance and normalize functionalities.

- Rood: focus on the sensory and motor functions in a similar way and activate muscles by sensory receptors.

- Bobath: is the most used neurodevelopmental treatment to improve tone, prevent abnormal primitive reflex patterns and allow automatic reactions.

- Vojta-European Method: based on the activation of the postural development and equilibrium reactions to stimulate a normal development.

- Conductive Education: based on theory that difficulties with motor dysfunction are problems of learning. 


\section{B. Robotized Rehabilitation}

Several are the advantages of robotic devices used for walking training (cf. illustration examlpes on Fig. 3). In fact, they can improve (i) endurance, (ii) balance \& coordination, (iii) strength, (iv) motor planning, and (v) confidence.

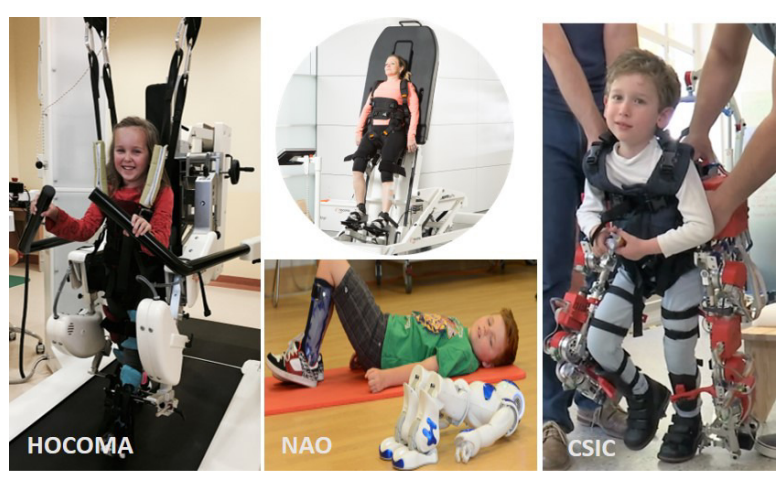

Fig. 3. Illustration of some robotic devices for kids rehabilitation

Achieving functional walking ability is an important goal for children, and such robotic systems [22] can be motivating and challenging. In fact, lower-limb exoskeletons are highly efficient in reducing the hard work of the physiotherapists. Moreover, they can guarantee a high number of repetitions (3300 steps per session vs 50-800 steps using standard therapy) as well as longer therapeutic sessions. In this paper, we are interested in the rehabilitation of kids aged from two to ten years old. The difference of kids age lead to a huge difference of morphology (limb lengths, masses, etc) which prove the necessity of good control aspects of the exoskeletons' joints.

\section{Control Related Issues}

The most fundamental part is to control the lower limb exoskeleton [23] using the performant and the adequate controller. In fact, the proposed controller should be robust against (i) the neglected dynamics in the model, (ii) the human-device contact and friction forces, and (iii) morphological related uncertainties. More specifically, the control strategies must be developed in order to follow the patient's movement intension and his motor abilities, despite, the variability of the children parameters (different masses and lengths, etc). It is also recommended that the developed controllers should do the same as a therapist exercises of gait scheme [24]. In this context, two controllers are proposed, a classical PD controller [25] and a robust sliding mode controller [26], in order to evaluate and compare their robustness towards parameter variations.

\section{Proposed Control Solutions}

\section{A. Simplified Model of the rehabilitation device}

The lower limb exoskeleton (Fig. 3) is a complicated system which allows the leg movements of kids. The effect of the motor training may produce the ability to rewalk again thanks to the brain plasticity. For this reason and in order to control it, a simplified model (two degrees of freedom) is proposed. The proposed simplified model includes the human leg and the exoskeleton[27].

$$
M(q) \ddot{q}+C(q, \dot{q}) \dot{q}+G(q)=\tau
$$

with,

$$
\begin{aligned}
& M_{11}=\frac{1}{8} l_{1}^{2} m_{1}+\frac{1}{4} m_{2}\left(\frac{1}{4} l_{2}^{2}+l_{1}^{2}+l_{1} l_{2} \cos q_{2}\right) \\
& +\frac{1}{2} m_{s}\left(l_{1}^{2}+l_{2}^{2} k_{2}^{2}+2 l_{1} l_{2} k_{2} \cos q_{2}\right) \\
& +\frac{1}{2} k_{1}^{2} l_{1}^{2} m_{t}+\frac{1}{2}\left(I_{1}+I_{2}+I_{s}+I_{t}\right) \\
& M_{12}=M_{21}=\frac{1}{2} m_{2}\left(\frac{1}{2} l_{2}^{2}+l_{1} l_{2} \cos q_{2}\right)+\left(I_{2}+I_{S}\right) \\
& +\frac{1}{2} m_{s}\left(l_{2}^{2} k_{2}^{2}+2 l_{1} l_{2} k_{2} \cos q_{2}\right) \\
& M_{22}=\frac{1}{8} m_{2} l_{2}^{2}+\frac{1}{2} m_{s} l_{1}^{2}+l_{2}^{2} k_{2}^{2}+\frac{1}{2}\left(I_{2}+I_{s}\right) \\
& C_{11}=\left(\frac{1}{2} m_{2}+m_{s} k_{2}\right) l_{1} l_{2} \sin q_{2} \\
& C_{12}=-\left(\frac{1}{2} m_{2}+m_{s} k_{2}\right) l_{1} l_{2} \sin q_{2} \\
& C_{21}=\left(\frac{1}{4} m_{2}+\frac{1}{2} m_{s} k_{2}\right) l_{1} l_{2} \sin q_{2} \\
& C_{22}=0 \\
& G_{1}=-\left(\frac{1}{2} m_{1}+m_{2}+k_{1} m_{t}+m_{s}\right) g l_{1} \sin q_{1} \\
& -\left(\frac{1}{2} m_{1}+m_{s} k_{2}\right) g l_{2} \sin \left(q_{1}+q_{2}\right) \\
& G_{2}=-\left(\frac{1}{2} m_{1}+m_{s} k_{2}\right) g l_{2} \sin \left(q_{1}+q_{2}\right)
\end{aligned}
$$

where:

$q=\left[\begin{array}{ll}q_{1} & q_{2}\end{array}\right]^{T} \in \mathbb{R}^{2}$ represents the position vector of the hip and knee joints, respectively,

$\dot{q}=\left[\begin{array}{ll}\dot{q}_{1} & \dot{q}_{2}\end{array}\right]^{T} \in \mathbb{R}^{2}$ is the speed vector,

$\ddot{q}=\left[\begin{array}{ll}\ddot{q}_{1} & \ddot{q}_{2}\end{array}\right]^{T} \in \mathbb{R}^{2}$ is the acceleration vector,

$M(q) \in \mathbb{R}^{2}$ is the inertia matrix, which is symmetric, uniformly bounded and positive definite,

$C(q, \dot{q}) \dot{q} \in \mathbb{R}^{2}$ represents the Coriolis, and centrifugal forces and torques,

$G(q) \in \mathbb{R}^{2}$ denotes the gravity torques,

$\tau \in \mathbb{R}^{2}$ is the vector of actuator torques,

$m_{1}, m_{2}, l_{1}, l_{2}$ represent the mass and length of thigh and shank segments of the exoskeleton, respectively,

$m_{t}, m_{s}$ denote thigh and shank masses of human limb,

$k_{1}, k_{2}$ are the position of the center of mass of thigh and shank segments, respectively,

$I_{1}, I_{2}, I_{S}, I_{t}$ represent the moments of inertia of thigh and shank of the exoskeleton and human limb, respectively, $g$ is the gravity acceleration.

\section{B. Proposed Controllers}

Two controllers are proposed. First, the proportionalderivative controller (PD controller) which is widely used in industrial applications. Its basic idea is to calculate the 
error value between the desired and the actual trajectories and then to apply a correction including proportional and derivative terms. Hence, the control input $\tau$ will be expressed by:

$$
\tau=-K_{p}\left(q-q_{d}\right)-K_{d}\left(\dot{q}-\dot{q}_{d}\right)
$$

$K_{d}$ and $K_{p}$ are positive feedback gains. $q_{d}$ and $\dot{q}_{d}$ are the desired trajectory and its velocity. Since the exoskeleton is dedicated to kids with different ages, a robust sliding mode control is also proposed. Such an advanced controller is mainly characterize by its robustness towards parameter variations. The sliding function can be expressed as:

$$
s=\dot{e}+\lambda e
$$

with $e$ is the tracking error, $\dot{e}$ is the velocity tracking error. It is required to take the system to the sliding surface Hence, in case of $s=0$, we obtain: $\dot{s}=0$, then we obtain successively:

$$
\begin{gathered}
\ddot{q}-\ddot{q}_{d}+\lambda\left(\dot{q}-\dot{q}_{d}\right)=0 \\
M^{-1}(\tau-C \dot{q}-G)-\ddot{q}_{d}+\lambda\left(\dot{q}-\dot{q}_{d}\right)=0
\end{gathered}
$$

We multiply by $M$, we obtain :

$$
\tau-C \dot{q}-G-M \ddot{q}_{d}+M \lambda\left(\dot{q}-\dot{q}_{d}\right)=0
$$

If $s \neq 0, \dot{s} \neq 0$, hence, to ensure robustness, we add to the equivalent control giving an ideal sliding mode, $\Delta \tau$, which is a high frequency discontinuous term

$$
\tau=\tau_{e q}+\Delta \tau
$$

with

$$
\tau_{e q}=C \dot{q}+G+M \ddot{q}_{d}-\lambda M\left(\dot{q}-\dot{q}_{d}\right)
$$

we obtain

$$
\dot{s}=M^{-1} \Delta \tau
$$

where

$$
\Delta \tau=-M K \operatorname{sign}(s)
$$

The Lyapunov function associated to the system is:

$$
V=\frac{1}{2} s^{T} s
$$

The objective of this choice consists to guarantee the minimization of $s$, and to goes to the sliding surface $s=0$. Moreover, remaining on the sliding surface, guarantees the convergence to zero of the error $e$. Then, the differential of $V$ with respect to time gives :

$$
\begin{gathered}
\dot{V}=s^{T} \dot{s} \\
\dot{V}=s^{T} M^{-1} \Delta \tau \\
\dot{V}=-s^{T} K \operatorname{sign}(s)<0
\end{gathered}
$$

with $K$ is diagonal positive matrix.

The major drawback of the sliding mode control is the chattering phenomenon presented in the variations of the control which can damage the actuators. In order to eliminate this phenomenon, we propose to replace the sign function by a smooth function as the hyperbolic tangent function defined as :

$$
\tanh (x)=\frac{e^{x}-e^{-x}}{e^{x}+e^{-x}}
$$

\section{Simulation Results}

The walking cycle reference trajectories were generated following the proposed method introduced in [28]. In this section, simulation results are presented of both controllers proposed in the previous subsection.
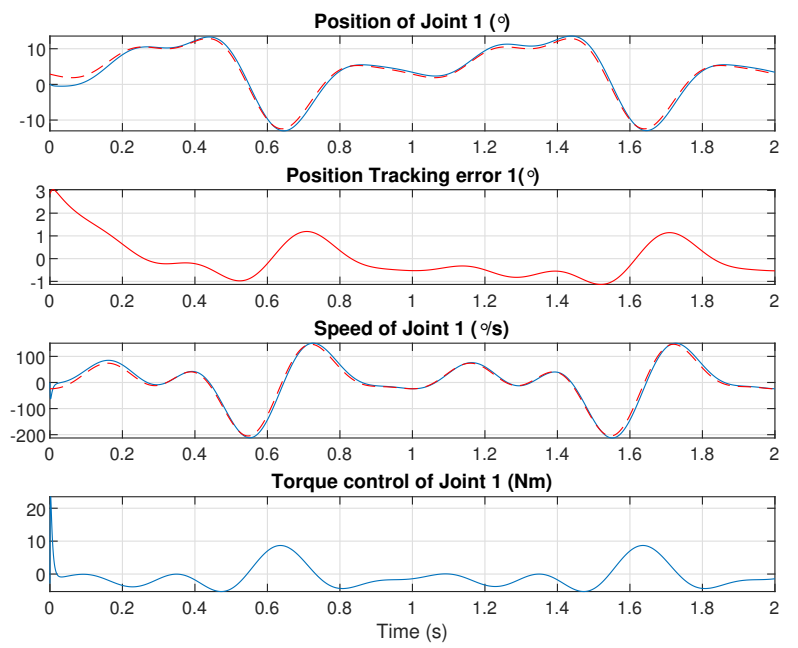

Fig. 4. Position, speed and torque control of the hip joint, obtained with a PD controller in the nominal case. solid line: actual trajectory, dashed line: desired trajectory.
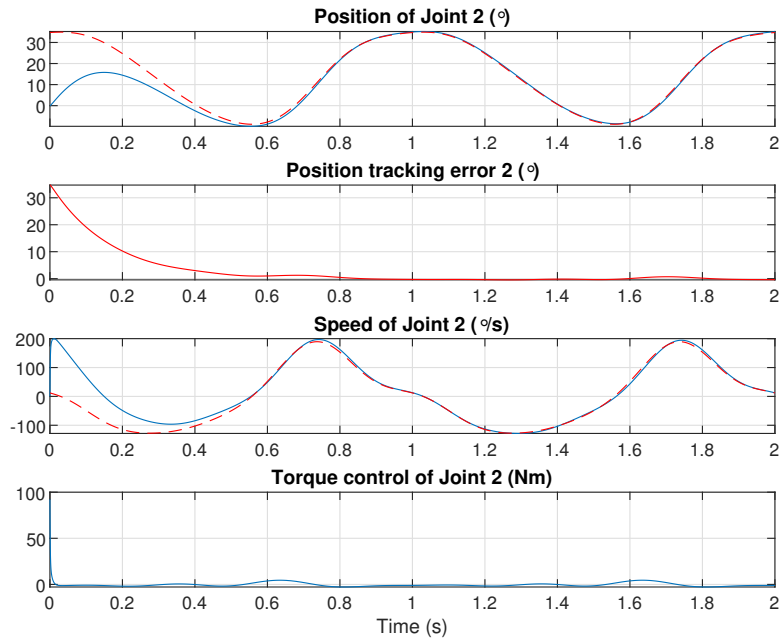

Fig. 5. Position, speed and torque control of the knee joint, obtained with a PD controller in the nominal case. solid line: actual trajectory, dashed line: desired trajectory.

Figures 4 and 5 show respectively the position evolution of the hip and the knee joints, the tracking error, their speed and their applied torques using a PD controller in 

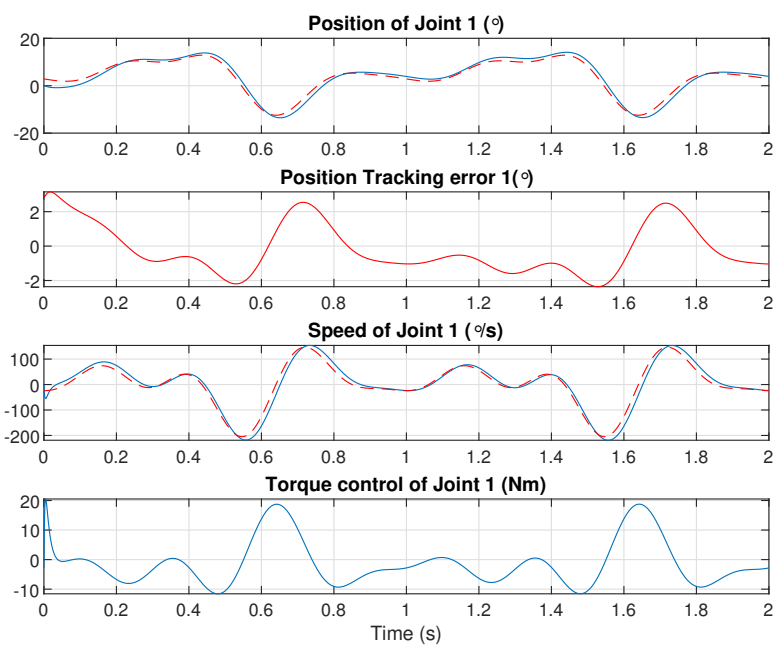

Fig. 6. Position, speed and torque control of the hip joint, obtained with a PD controller with $+50 \%$ and $+25 \%$ of the leg mass and length variations, respectively. solid line: actual trajectory, dashed line: desired trajectory.
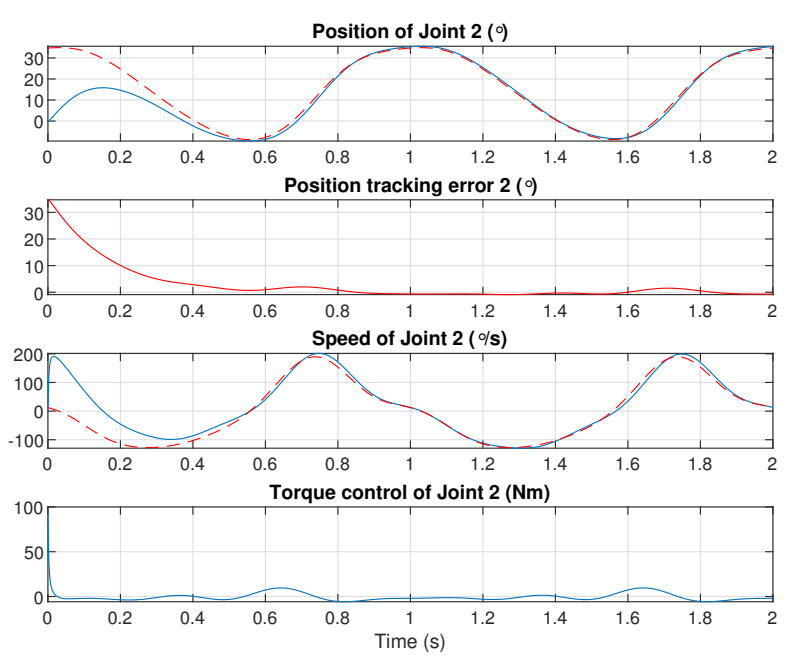

Fig. 7. Position, speed and torque control of the knee joint, obtained with a PD controller with $+50 \%$ and $+25 \%$ of the leg mass and length variations, respectively. solid line: actual trajectory, dashed line: desired trajectory.

the nominal case. In order to test the robustness of this controller, parameter variations are considered. Due to the different morphologies of children between 2 and 10 years old, we have tested the case when $+50 \%$ and $+25 \%$ of the leg mass and length changes, respectively. Figures 6 and 7 show that the trajectories follow the desired gait but with a significant tracking errors and the torques become high. Hence, it is proved that the PD controller is not robust against parameter variations.

In the sequel, simulation results of a robust sliding mode controller are presented. Two scenarios have been introduced: the first in the nominal case (Figs. 8 and 9) and the second, with parameter variations (Figs. 10 and 11). These figures show the robustness of this controller thanks to a good tracking of trajectories for the hip and the knee joints with performant torques values.
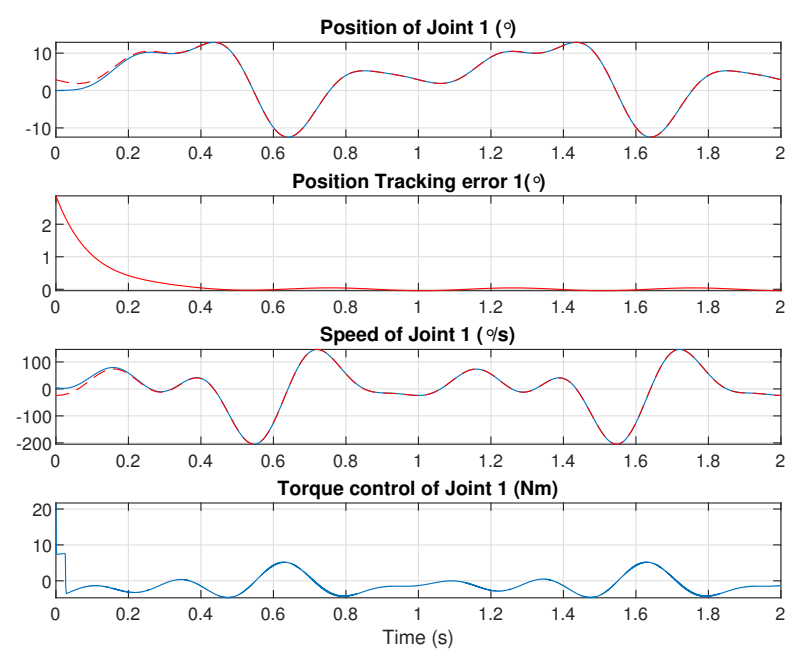

Fig. 8. Position, speed and torque control of the hip joint, obtained with a sliding mode controller in the nominal case. solid line: actual trajectory, dashed line: desired trajectory.
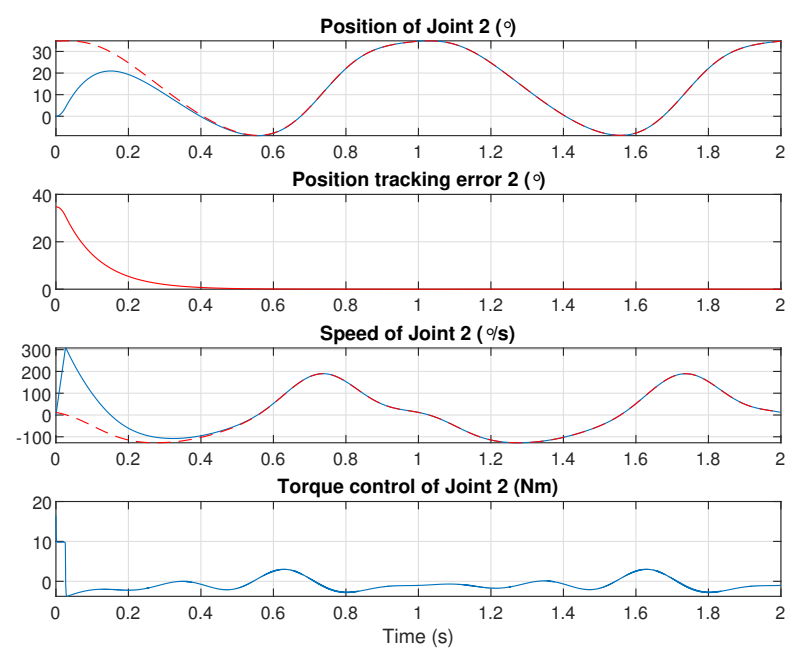

Fig. 9. Position, speed and torque control of the knee joint, obtained with a sliding mode controller in the nominal case. solid line: actual trajectory, dashed line: desired trajectory.

\section{CONClusion And Future Work}

In the present paper, an overview about the cerebral palsy disease is presented. Research studies show that with extensive training sessions, kids suffering from cerebral palsy can restore their walking mobility. In this context, two controllers have been proposed and implemented into a simplified model of exoskeleton used for rehabilitation. Through simulations, it has been shown that the sliding mode controller is robust against parameter variations contrary to the PD controller. In future work, a deeply study on the model of the exoskeleton will be addressed. The proposed controllers will be implemented on the real exoskeleton and tested on healthy child first, then on cerebral palsy children population in cooperation with clinical staff of rehabilitation.

\section{REFERENCES}

[1] D. J. Reinkensmeyer, V. Dietz, Neurorehabilitation Technology, in Springer Int. Publishing, 2nd Ed., 2016. 

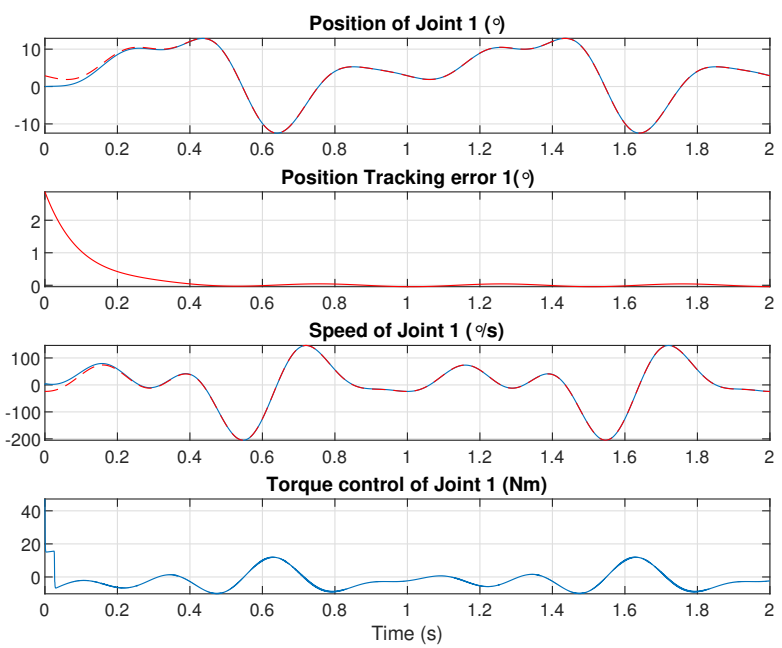

Fig. 10. Position, speed and torque control of the hip joint, obtained with a sliding mode controller with $+50 \%$ and $+25 \%$ of the leg mass and length variations, respectively. solid line: actual trajectory, dashed line: desired trajectory.
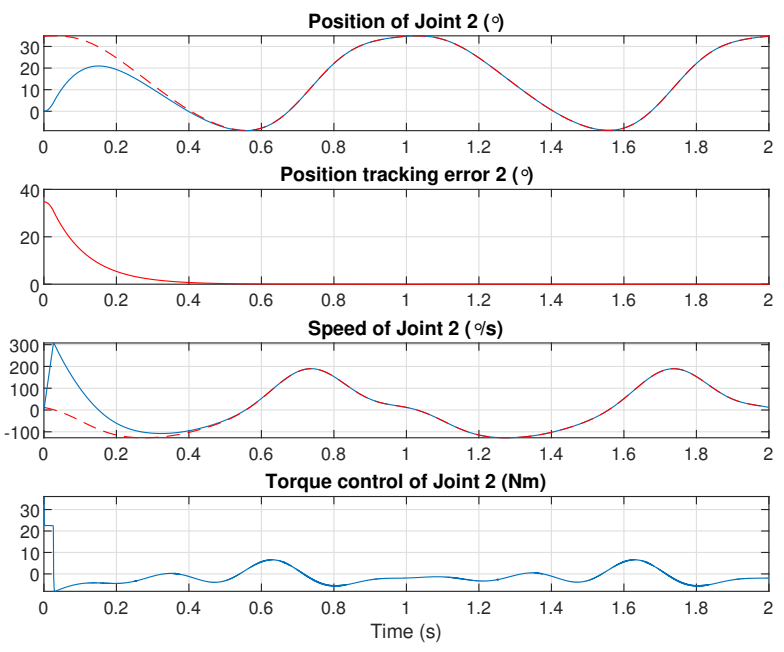

Fig. 11. Position, speed and torque control of the knee joint, obtained with a sliding mode controller with $+50 \%$ and $+25 \%$ of the leg mass and length variations, respectively. solid line: actual trajectory, dashed line: desired trajectory.

[2] C. Bayón, O. Ramirez, M.D. Del Castillo, J.I. Serrano, R. Raya, J.M. Belda-Lois, R. Poveda, F. Mollà, T. Martin, I. Martnez, S. L. Lara and E. Rocon, CPWalker: Robotic Platform for Gait Rehabilitation in Patients with Cerebral Palsy, in IEEE Int. Conf. on Robotics and Automation, pp. 3736-3741, 2016.

[3] G. Sumathy, A. Renjith. A Survey of Vision and Speech Stimulation for cerebral Palsy Rehabilitation, in Int. Conf. on Control, Instrumentation, Communication and Computational Technologies, pp. 13151319, 2014.

[4] M. Bax, M. Goldstein, P. Rosenbaum, A. Leviton, N. Paneth, Proposed definition and classification of cerebral palsy, in Developmental Medicine and Child Neurology. vol. 47, pp. 571-576, 2005.

[5] M. Stavsky, O. Mor, S. A. Mastrolia, S. Greenbaum, N. G. Than, O. Erez, Cerebral Palsy-Trends in Epidemiology and Recent Development in Prenatal Mechanisms of Disease, Treatment, and Prevention, in Front. Pediatr. vol. 21, pp. 1-10, 2017.

[6] KB. Nelson, JH. Ellenberg, Antecedents of cerebral palsy. Multivariate analysis of risk, in N. Engl. J. Med. vol. 2, pp. 81-86, 1986.

[7] E. Blair, F. Stanley, When can cerebral palsy be prevented? The generation of causal hypotheses by multivariate analysis of a casecontrol study, in Paediatr Perinat Epidemiol vol. 3, pp. 272-301, 1993.
[8] JK. Grether, KB. Nelson, Maternal infection and cerebral palsy in infants of normal birth weight, in JAMA vol. 3, pp. 207-211, 1997.

[9] TM. O'Shea, EN. Allred, O. Dammann, D. Hirtz, KCK. Kuban, N. Paneth, et al., The ELGAN study of the brain and related disorders in extremely low gestational age newborns, in Early Hum Dev. vol. 11, pp. 719-725, 2009.

[10] H. Barbeau, S. Rossignol, Enhancement of locomotor recovery following spinal cord injury, in Curr Opin Neurol. vol. 6, pp. 517-524, 1994.

[11] F. Patané, S. Rossi, F. Del Sette, J. Taborri, P. Cappa, WAKE-Up Exoskeleton to Assist Children With Cerebral Palsy: Design and Preliminary Evaluation in Level Walking, in IEEE Trans. ON Neural Systems and Rehabilitation Engineering, vol. 25, pp. 906-916, 2017.

[12] M. Wu, J. Kim, P. Arora, D. J. G-Spira, Y. Zhang, Locomotor training through a 3D cable-driven robotic system for walking function in children with cerebral palsy: a pilot study, in IEEE Int. Conf of Engineering in Medecine and Biology Society, pp.3529-3532, 2014.

[13] A. Deep, R. Jaswal, Role of Management \& Virtual Space for the Rehabilitation of Children Affected with Cerebral Palsy: A Review, in IEEE Int. Conf on Signal Processing, Computing and Control, pp. 293-299, 2017.

[14] O. N. Berdina, T. A. Bairova, L. V. Rychkova, S. A. Sheptunov, The Pediatric Robotic-Assisted Rehabilitation Complex for Children and Adolescents with Cerebral Palsy: Background and Product Design, in Int. Conf. Quality Management, Transport and Information Security, Information Technologies, pp. 360-363, 2017.

[15] A. J. McDaid, C. Lakkhananukun, J. Park, Paediatric robotic gait trainer for children with cerebral palsy, in IEEE Int. Conf. on Rehabilitation Robotics, pp. 780-785, 2015.

[16] G. C. Burdea, D. Cioi, A. Kale, W. E. Janes, S. A. Ross, J. R. Engsberg, Robotics and Gaming to Improve Ankle Strength, Motor Control, and Function in Children With Cerebral PalsyA Case Study Series, in IEEE Trans. Neural Systems and Rehabilitation Engineering, vol. 21, pp. 165-173, 2013.

[17] D. Ganjwala, Multilevel orthopedic surgery for crouch gait in cerebral palsy: An evaluation using functional mobility and energy cost, in Indian J. Orthop., vol. 45, no. 4, pp.314-319, 2011

[18] K. Tedroff, K. Löwing, K. D. N. Jacobson, and E. Aström, Does loss of spasticity matter? a 10-year follow-up after selective dorsal rhizotomy in cerebral palsy, Dev. Med. Child Neurol., vol. 53, no. 8, pp. 724-729, 2011.

[19] B. C. Friedman, R. D. Goldman, Use of botulinum toxin a in management of children with cerebral palsy, in Can. Fam. Physician, vol. 57, no. 9, pp. 1006-1073, 2011

[20] F. Mahamud, A. Anuar, Usage of Robotic Rehabilitation Technology for Lower Limbs Therapy of Children with Cerebral Palsy - A Review, in IEEE Int. Symposium on Robotics and Manufacturing Automation, pp. 126-130, 2014.

[21] S. Cuccurullo, Physical Medicine and Rehabilitation Board Review, in Demos Medical Publishing, 2004.

[22] H. Rifai, M. S. Ben Abdessalem, A. Chemori, S. Mohammed, Y. Amirat. Augmented L1 Adaptive Control of an Actuated Knee Joint Exoskeleton: From Design to Real-Time Experiments, in IEEE Int. Conf. on Robotics and Automation, pp. 5708-5714, 2016.

[23] C. Copilusi, C. Ploscaru, Exoskeleton for children walking rehabilitation: theoretical studies and simulation, in IEEE Int. Conf. on Automation, Quality and Testing, Robotics, 2016.

[24] F. Barroso, C. Santos, J. C. Moreno, Influence of the robotic exoskeleton Lokomat on the control of human gait: an electromyographic and kinematic analysis, in 3rd Portuguese Meeting in Bioengineering, 2013.

[25] J. Chen, J. Hochstein, C. Kim, D. Damiano, T. Bulea, Design Advancements toward a Wearable Pediatric Robotic Knee Exoskeleton for Overground Gait Rehabilitation, in IEEE Int. Conf. on Biomedical Robotics and Biomechatronics, pp. 37-42, 2018.

[26] M. Babaiasl, S. N. Goldar, M. H. barhaghtalab, V. Meigoli, Sliding Mode Control of an Exoskeleton Robot for Use in Upper-Limb Rehabilitation, in Int. Conf. on Robotics and Mechatronics, pp. 694701, 2015.

[27] Ghezal, M. Guiatni, I. Boussioud and C. S. Renane. Design and Robust Control of a 2 DOFs Lower Limb Exoskeleton, in Int. Conf. on Communications and Electrical Engineering, 2018.

[28] S. Mefoued. Commande robuste référencée intention d'une orthèse active pour l'assistance fonctionnelle aux mouvements du genou. Ph.D. Université Paris-Est, 2012. 